\title{
Rusty bolts: planning for corrosion of ground support in underground mines
}

\author{
RP Preston Golder Associates Inc., Canada \\ JM Roy Golder Associates Inc., Canada \\ RP Bewick Golder Associates Inc., Canada
}

\begin{abstract}
Steel ground support elements installed in underground excavations are exposed to groundwater and atmospheres that can cause corrosion of the steel and thus a loss of support capacity over time. For high tonnage mines, where in some cases, hundreds of kilometres of drifts may be excavated, the ground support must be maintained for long periods of the mine life. Ground support corrosion must therefore be considered early in the planning process and this paper discusses an approach to classify the possible corrosive conditions in a mine, estimate ranges of possible corrosion rates and develop hazard maps that can be used to develop forecasts of loss of support capacity and timing of rehabilitation. Currently available corrosion protection technologies are also discussed and compared qualitatively. Better understanding of ground support corrosion can improve health and safety, reduce costly delays to production due to the ability to schedule support replacement in the mine plan and provide mine managers with more realistic forecasts of ground support costs and equipment needs over the life-of-mine.
\end{abstract}

Keywords: ground support, corrosion, mine plan, mine schedule

\section{Introduction}

High tonnage mining methods (mass mining) are becoming more popular in the mining industry to exploit deep and low-grade deposits that may not be economic to mine with open pits. These mines require the development of, sometimes, hundreds of kilometres of tunnels and mass excavations to access the orebody, mine and transport the ore from underground to surface. Further, these excavations must be serviceable for long periods of time (e.g. sometimes greater than 20 years). As such, it is important to understand how corrosion of the steel ground support elements installed in these mines can reduce the serviceability of the ground support systems, create potentially unforeseen hazards and impact the mine schedule. In this article, a framework for corrosion potential forecasting in underground mining environments is outlined and potential mitigation options available to the mining industry are discussed.

Corrosion of steel ground support elements is a common problem in underground environments that has been extensively researched in both mining and civil engineering applications. Corrosion can be classified as aqueous or atmospheric, which are both driven by environmental variables such as temperature, humidity, flow rates, total dissolved solids and chemistry (Dorion et al. 2009, 2015; Dorion \& Hadjigeorgiou 2014; Dorion 2013; Roberge 2000, 2008; Hassell et al. 2004, 2007; Charette et al. 2004; Charette 2003; Gamboa \& Atrens 2003; Li \& Lindblad 1999; Hutchinson \& Diederichs 1996; Heidersbach 1990). The corrosion rates experienced in a mine can vary greatly depending on these environmental variables and it is thus critical to characterise these variables ahead of and during mining to understand corrosion potential.

While atmospheric corrosion is commonly observed underground on surface ground support elements such as steel mesh and straps, aqueous corrosion may be occurring behind the scenes within the rock mass which could be diminishing the support capacity of steel rockbolts and creating an unseen hazard. Aqueous corrosion is also generally considered to be more aggressive than atmospheric corrosion with the potential 
for highly localised corrosion mechanisms such as pitting and stress corrosion cracking (Hassel et al. 2007; Gamboa \& Atrens 2003). As such, aqueous corrosion is discussed in greater detail within this article.

\section{Corrosive mining environments}

Underground mines are often wet, warm and humid places that can create the perfect conditions for corrosion to take place. A review of the available literature on corrosion in mining, civil and industrial applications has been conducted to classify the types of mining conditions that lead to corrosion of ground support elements in mines. Generally, corrosion can be classified as aqueous or atmospheric with sub-classes identified based on specific ranges of environmental variables which can be relatively easily measured in the field. The following sub-sections summarises the types of corrosion that may be encountered in an underground metalliferous mine.

\subsection{Aqueous corrosion}

Aqueous corrosion is commonly a problem in mass mines because of their depth, geology and groundwater flow regimes. Both groundwater and surface water can preferentially flow into the mining area as a result of the mined zones increasing local permeability. In the case of mass mines, which tend to be designed around exploitation of large ore deposits which have dispersed and concentrated sulphide minerals, these conditions can contribute to the acidification of groundwater. Further, naturally occurring ion species in the groundwater could also be corrosive and their concentrations may be increased due to exposure of large surface areas of broken rock from mining activities.

Roy et al. (2016) conducted a literature review of aqueous corrosion and identified three primary aqueous corrosive environments: acidic (pH of less than 4) (Roberge 2008), neutral pH (pH between 4 and 10) with low salinity (Dorion 2013) and neutral pH with high salinity (Hassell et al. 2007) (Figure 1). A large mine could have ground support that is exposed each of these different aqueous corrosive environments and spatial characterisation is thus required as the corrosion mechanisms and possible rates will vary.

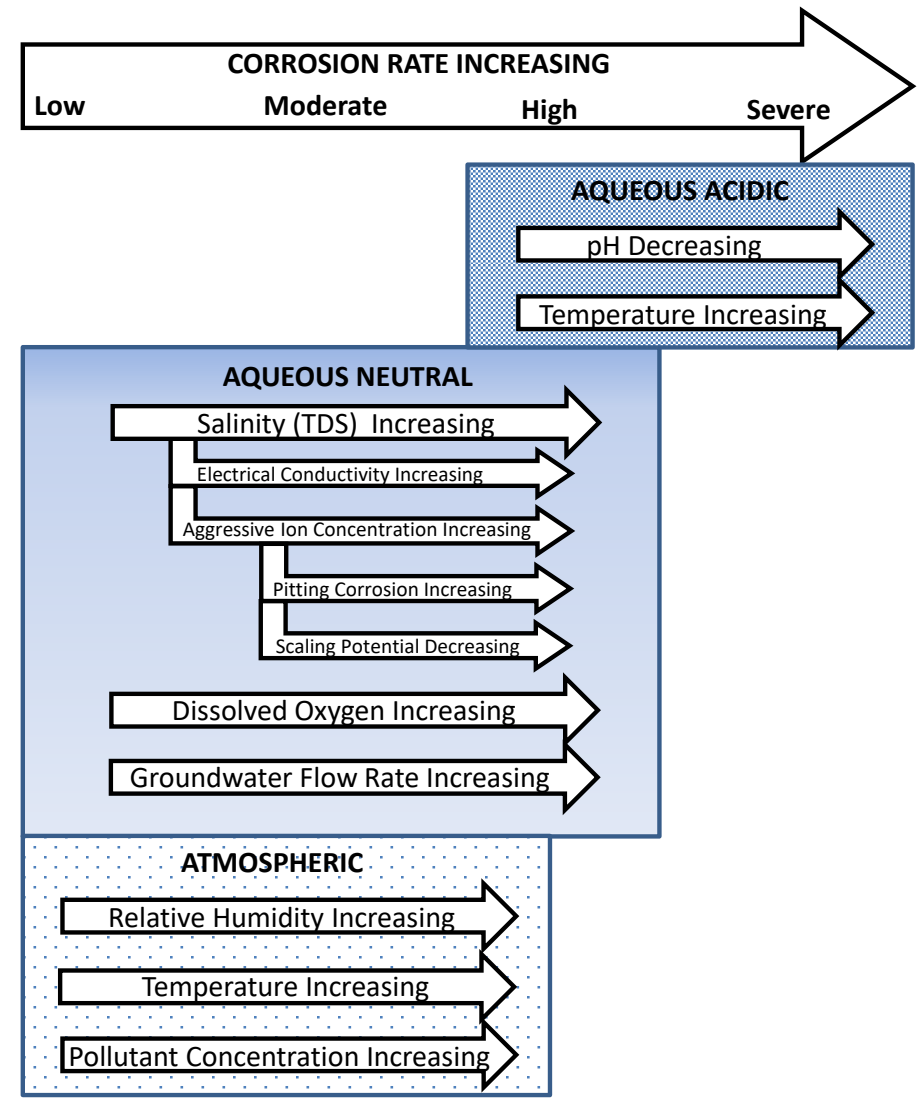

Figure 1 Classes of corrosive environments and the key variables which affect corrosion rates 
In the case of exposure of steel to acidic water, $\mathrm{pH}$ and temperature are the main factors influencing corrosion rates, with low $\mathrm{pH}$ and high temperatures resulting in the highest rates of corrosion (Roberge 2008). In addition to uniform corrosion (i.e. even corrosion of the surface of the steel), acidic conditions are also more likely to result in a highly localised corrosion mechanism termed stress corrosion cracking which is a result of high concentrations of hydrogen ions which can promote hydrogen embrittlement of steel (Gamboa \& Atrens 2003).

Corrosion with neutral pH water is mainly controlled by salinity (measured as total dissolved solids (TDS) or by conductivity as a proxy) and dissolved oxygen (DO) (Hassell et al. 2007; Dorion 2013). However, the presence of certain aggressive ion species (e.g. chlorides, sulphates, iron and copper) can lead to rapid and localised pitting corrosion (Schweitzer 2007). Conversely, certain mineral scales that deposit on the steel can protect from corrosion (Hassell et al. 2007), but it is recommended for conservatism that this mechanism not be considered for preliminary assessments.

\subsection{Atmospheric corrosion}

Air pollutants, high atmospheric temperatures and high relative humidity are commonly experienced in mass mines which can promote corrosion of exposed ground support such as steel mesh, plates and straps. Atmospheric corrosion has been correlated to concentrations of pollutants such as diesel exhaust, blasting gases and rock dust as well as, air temperature, relative humidity and airflow rates (Dorion 2013; Hassell et al. 2007). Of these variables, relative humidity and temperature were found to have the greatest impact on atmospheric corrosion.

Corrosion rates have been shown to double for every $10^{\circ} \mathrm{C}$ increase in temperature (Hassell et al. 2007); however, above approximately $40^{\circ} \mathrm{C}$ the relative humidity tends to drop, resulting in decreased rates (Roberge 2000). Relative humidity was found to strongly influence corrosion rates between $60-100 \%$ relative humidity and atmospheric corrosion was not observed below $60 \%$ relative humidity.

Airflow rates and pollutant concentration can be combined into three broad air types: exhaust air, mixed air and stagnant air (Dorion 2013). Of the three air types, stagnant air was found to be the most corrosive, followed by exhaust air (Dorion 2013). The presence of $\mathrm{SO}_{2}$ gas was also found to increase corrosion rates (Dorion 2013).

\subsection{Summary of corrosive environments and possible rates}

In any mine, it is possible that multiple different corrosive environments can exist. These can be classified as aqueous acidic, aqueous neutral and atmospheric. Figure 1 shows a summary of these corrosion environments and the variables which impact the relative rate of corrosion possible.

Corrosion of ground support, by nature of the complex mechanisms, can range from being extremely localised to very uniform, with a wide range of corrosion rates possible. Thus, estimating absolute corrosion rates for any given area is challenging as the localisation depends on many factors. However, for the purposes of assessing corrosion potential across a mine, it is helpful to have a concept of the range of uniform corrosion rates that may be experienced based on the key environmental variables discussed identified in Figure 1. Figures 2 and 3 summarise possible corrosion regimes and estimated rates (i.e. uniform corrosion of unprotected steel) that could be encountered in a mining environment for aqueous and atmospheric corrosion, respectively. 


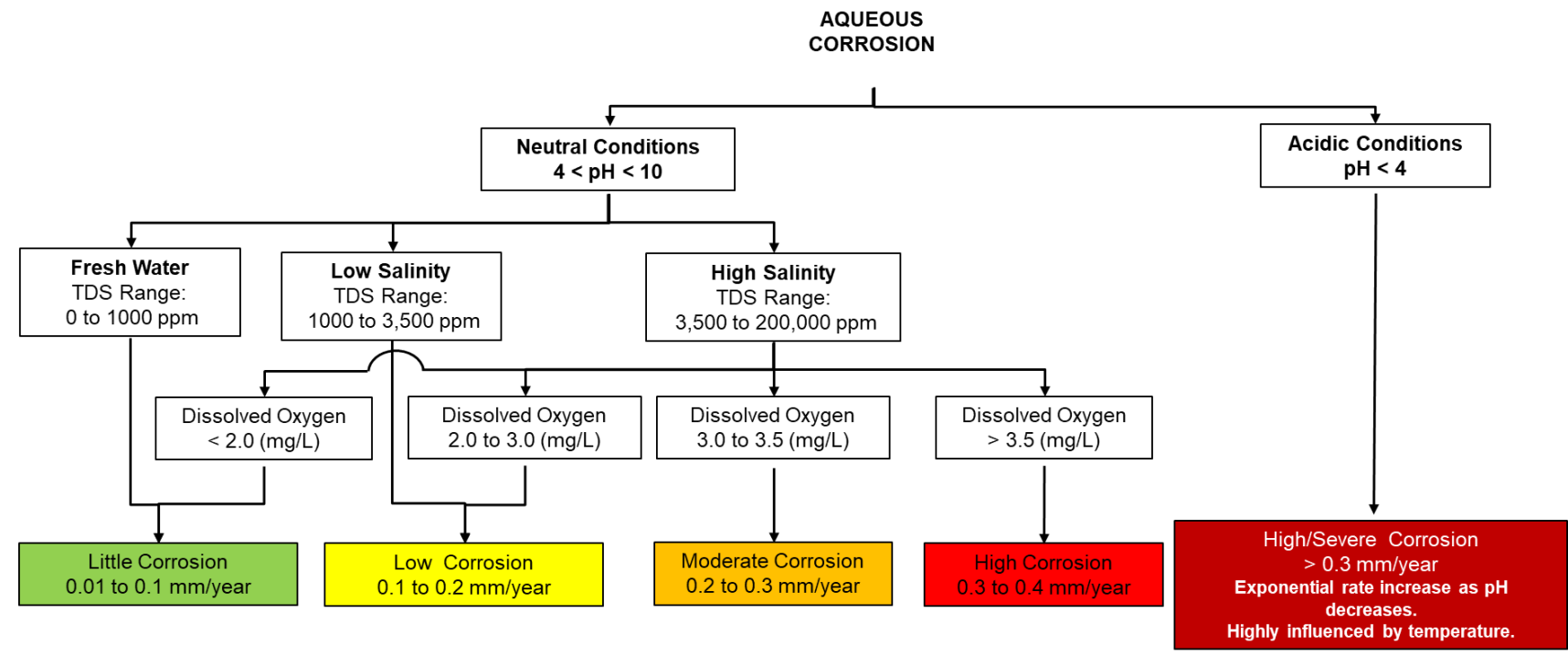

Figure 2 Classification of aqueous corrosive environments and estimated uniform corrosion rates for carbon steel (adapted from Roy et al. 2016)

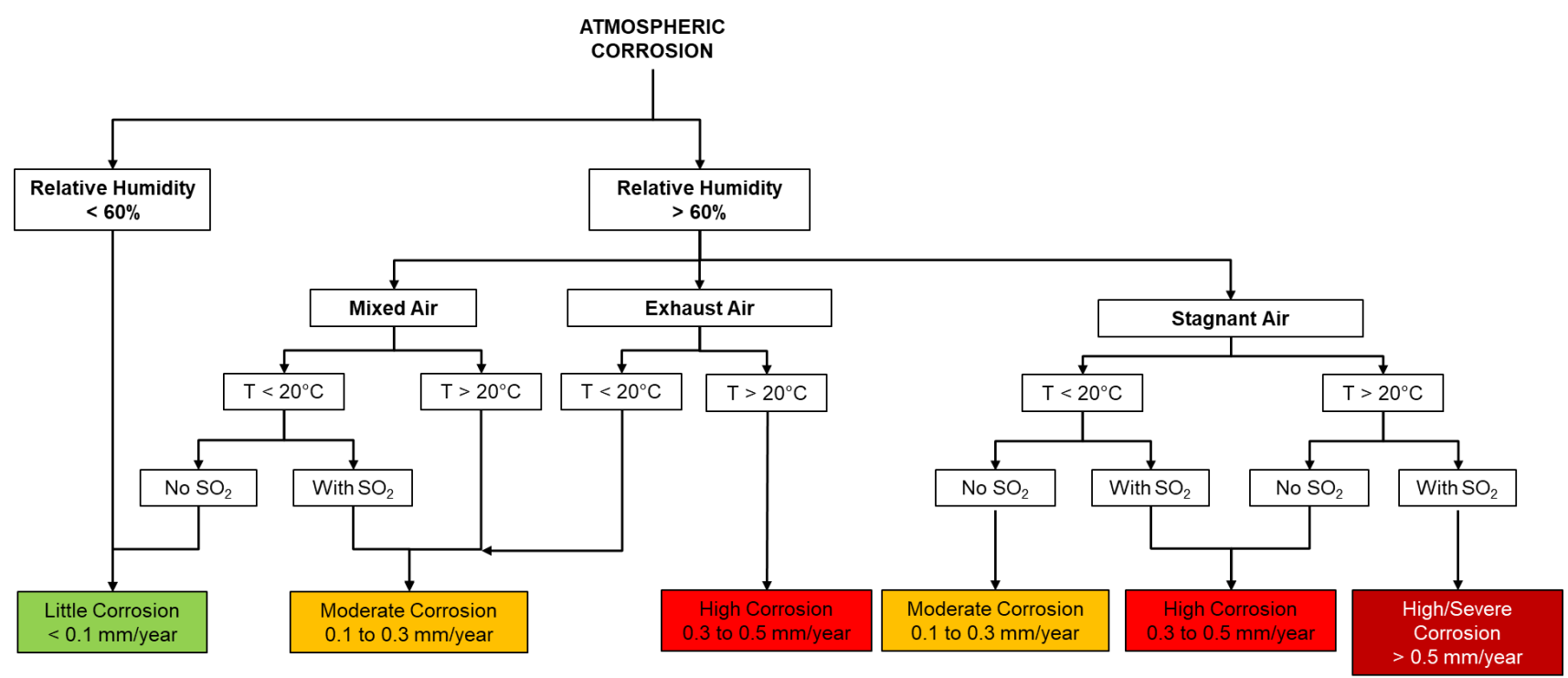

Figure 3 Classification of atmospheric corrosive environments and estimated uniform corrosion rates for carbon steel (based on Dorion 2013)

\section{Assessing corrosion potential in the mine}

Based on the three corrosive environments and the key rate controlling variables identified in Figures 2 and 3 , this section discusses the assessment of corrosion potential in a mine from the pre-mining stages (i.e. permitting or early development) to mine operation. The approach involves identification of corrosion potential on a mine-wide basis followed by sampling programs to develop spatial relationships which can feed into hazard mapping. 


\subsection{Early identification of corrosion potential}

During permitting phases of mine development, many jurisdictions require mines to provide forecasts of water quality over the lifetime of the mine. These forecasts include mine water $\mathrm{pH}$ and presence of metal ions which are sometimes characterised using kinetic tests. In addition, the geochemical and metallurgical characterisation of waste and ore rock required for permitting and planning can provide valuable insights into potential corrosion environments when combined with initial water chemistry measurements. Thus, for early identification of aqueous corrosion potential in a mine, it is possible to utilise the water quality characterisation typically used for permitting processes in combination with Figure 2. However, this approach will result in a very generalised assessment that later needs to be supplemented with a sampling program to identify spatial variability across the mine.

In terms of atmospheric corrosion, early identification of corrosion potential is challenging but a basic understanding of the ventilation network and mining equipment (i.e. diesel versus electric) can provide some indication of where atmospheric corrosion may be of concern (e.g. exhaust drifts where pollutants are concentrated).

\subsection{Water sampling}

Once mining is underway, a sampling program to identify the spatial potential for corrosion within a mine and possible rates should be implemented at a frequency to sufficiently capture changes in the conditions (i.e. evolution of groundwater flows and water quality). Baseline sampling at a higher frequency (e.g. monthly) is recommended early in the mine life to establish a reasonable frequency for the program. As discussed earlier, it is possible that much of the required data is being collected for other reasons and information sharing between mine departments (e.g. environmental and geotechnical groups) may yield sufficient data for a corrosion assessment.

The basic workflow of the water sampling program is as follows:

- Record the location and time of assessment.

- Record the groundwater condition, i.e. flow rate and associated fractures.

- Where groundwater is observed, collect a sample and test with a hand probe (TDS, DO, temperature, $\mathrm{pH}$ ).

- Reserve a certain number of water samples for laboratory analysis.

Water sampling should be conducted across the mining footprint with a focus on identifying areas with changes in flow rate, local geology and adjacent geology through which the water may flow. Where groundwater is observed underground, flow rates can be classified using categories such as those stated in the Rock Mass Rating system (RMR) (Bieniawski 1989).

When sufficient groundwater flows are encountered such that a sample can be collected, a small hand held type probe can be used to measure the key indicators of potential aqueous corrosion: (i.e. DO, TDS (sometimes measured as conductivity), temperature and $\mathrm{pH}$ ). These measurements are typically conducted as part of routine environmental groundwater sampling programs and easily tested for onsite, often with small, hand-held probes. These data can then be examined with reference to Figure 2 to determine the likely corrosion regime (acidic, neutral and low-salinity or, neutral and high salinity) and estimate expected rates. The relevant variables can then be contoured onto level plans or mine models and used in hazard zoning (discussed in Section 4).

In addition, a certain number of water samples should be reserved for laboratory testing to identify the presence of aggressive ions which can contribute to more rapid pitting corrosion (e.g. chlorides, sulphates, iron and copper). The presence of aggressive ions should be verified early in the mine development and as flow regimes change or if ground support failure is observed. 


\subsection{Atmospheric sampling}

Atmospheric testing may be less intensive and should focus on temperature and relative humidity. The mine ventilation plan should then be reviewed to identify areas of mixed air, exhaust and stagnant air. Sampling can be conducted to determine contaminant concentrations but this is less important. Like aqueous corrosion, these values should be graphically represented on mining plans and the values used to determine likely corrosion regimes and possible rates using Figure 3.

\section{$4 \quad$ Developing corrosion hazard maps}

Hazard maps are a useful visualisation platform to identify mine areas that may be at risk of corrosion of ground support elements. Other considerations for ground support related hazard maps that are not discussed in this article include bulking, squeezing, swelling and burst-prone conditions, as well as adverse geological structures. It is possible in certain mining environments (e.g. cave mining) that the ground support is strained to capacity due to stress induced ground deformations prior to the impacts of corrosion being of concern. Thus, the corrosion aspects identified in this article are only one component of a holistic ground support assessment.

The basic workflow for corrosion hazard mapping is as follows:

- Overlay the results of the water sampling program on mine layouts and cross reference with geological maps to identify corrosion environment zones. In the case of atmospheric corrosion, cross reference air samples with ventilation plans.

- Estimate corrosion rates for the mine using Figures 2 and 3.

- Estimate support capacity loss based on the cross-sectional area of the support and the estimated corrosion rates.

- Compare estimates of support capacity loss due to corrosion against models of support strain. Determine the controlling factor and schedule ground support replacement accordingly.

- Ground truth the model as mining progress and re-start the hazard mapping cycle. If required, add complexity to the model to account for ground support corrosion protection measures.

This workflow is discussed in greater detail in the following subsections.

\subsection{Corrosive environment zonation}

Modern mines typically use 3D block models and 3D wireframe models to characterise the mine geology. Block models often contain attributes such as sulphide concentration and rock type while the wireframe models delineate geological structures (an example is shown in Figure 4 overlain on a mine plan drawing). These geological data can be cross referenced with the results of a water sampling program and groundwater conditions (Figure 5) to delineate areas with different corrosion environments (e.g. areas of high sulphide concentration may be associated with water samples with low $\mathrm{pH}$ while dry areas may be located far from any geological structures). This process requires engineering judgement and later ground truthing to validate the model as mining progresses.

The correlated data can then be input into a block model or simply overlain on mine plans to identify hazard zones (Figure 6) and characterise the expected corrosion rates across the mine (using Figures 2 and 3 ). 


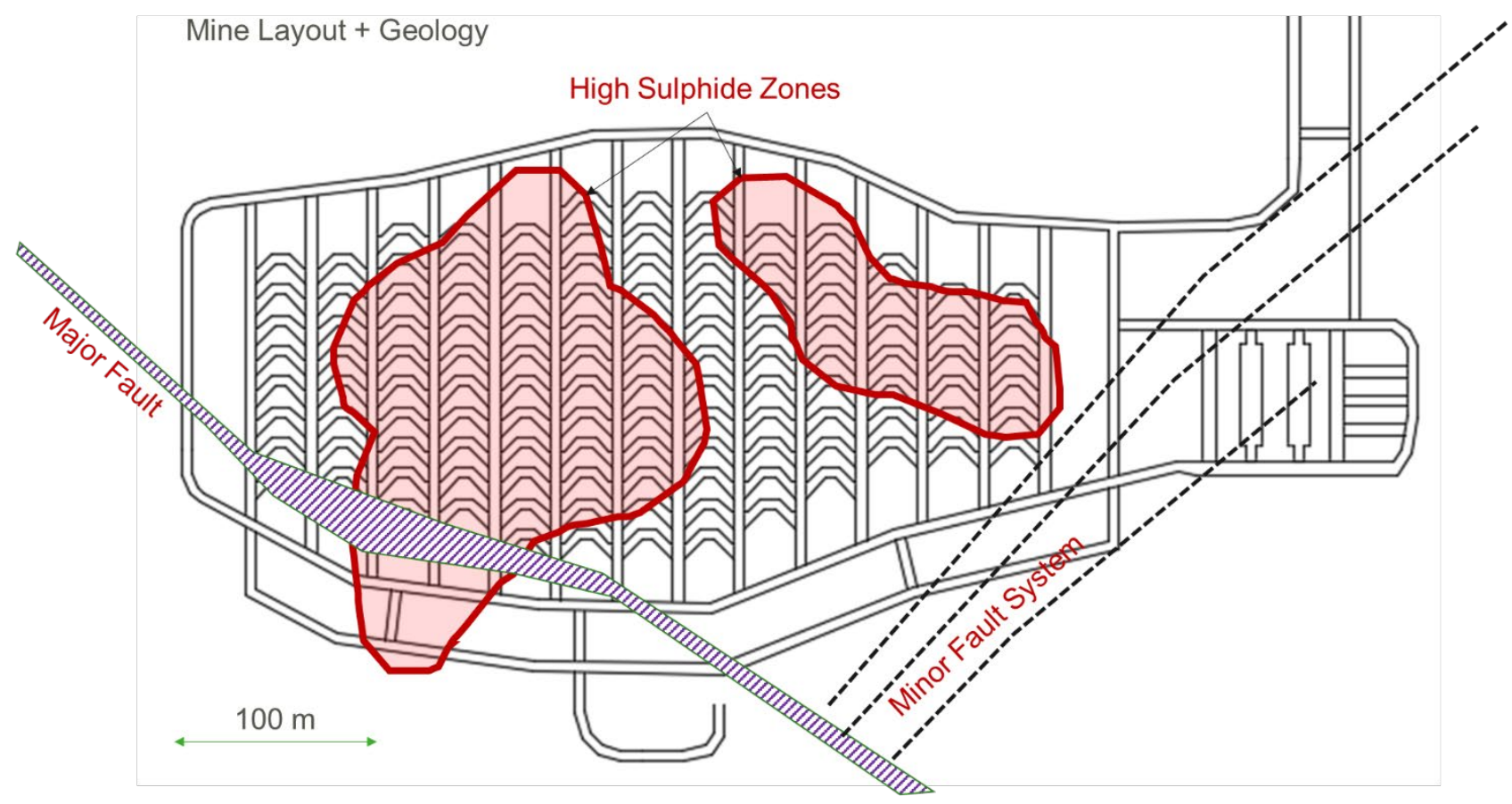

Figure $4 \quad$ Mine plan drawing with high sulphide and fault zones identified

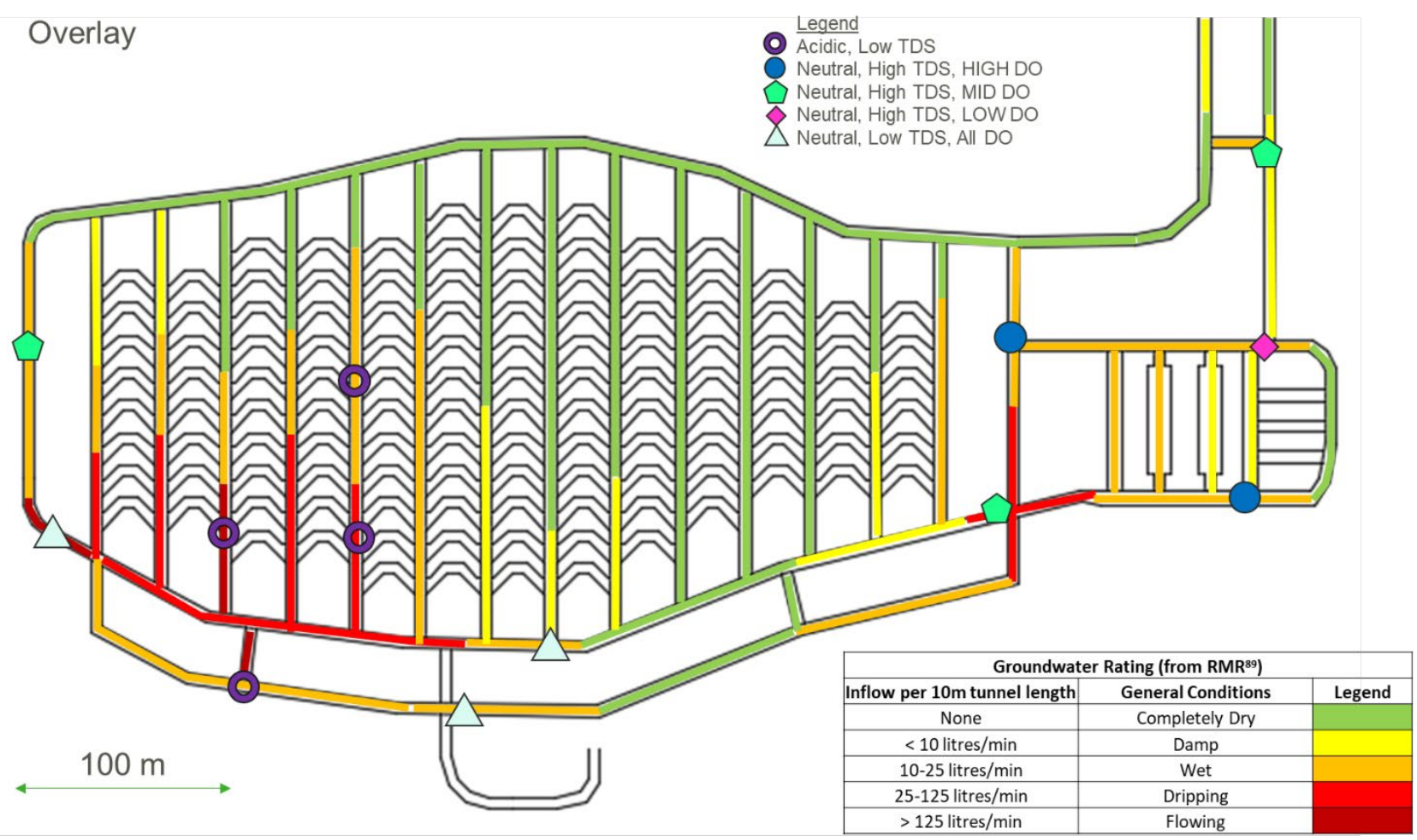

Figure 5 Mine plan drawing with water chemistry $(\mathrm{pH}$, total dissolved solids (TDS) and dissolved oxygen (DO)) and flow rate measurements 


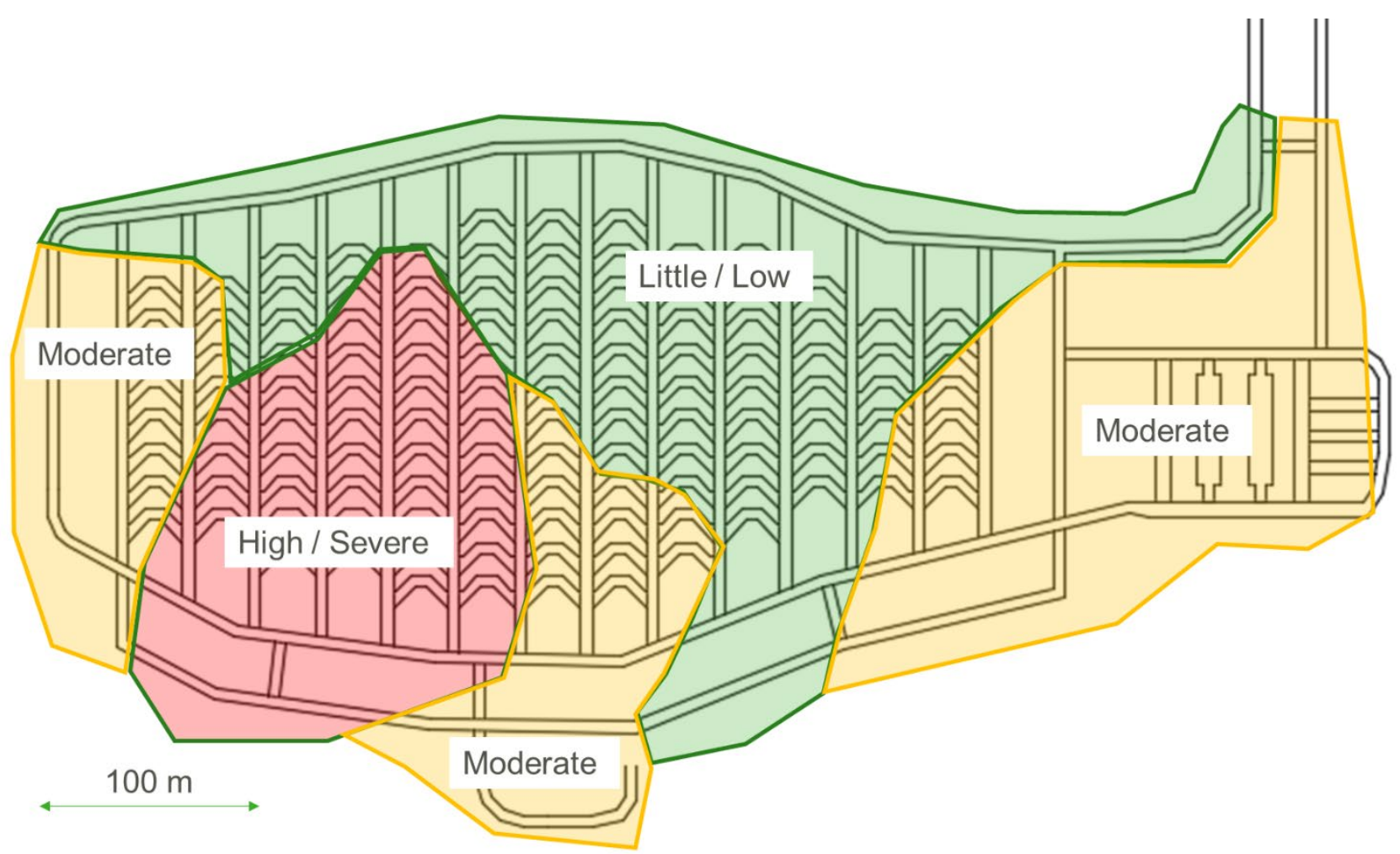

Figure 6 Mine plan drawing with resulting corrosion hazard zones overlain

\subsection{Estimating support capacity loss}

The estimated corrosion rates can be used to estimate a rate of ground support capacity loss over time based on the ground support element's cross-sectional area. The authors' experience is that ground support linearly loses strength until it effectively fails once $30 \%$ of the cross-sectional area is lost. Once the loss of capacity is estimated based on corrosion rates, the expected convergence rate from numerical modelling or other measures of estimated service life should be cross referenced to determine the controlling factor for the ground support elements. These data and associated calculations can be integrated into a block model for ease of visualisation and data processing.

Using this simple model, ground support replacement schedules can be developed for the mine. These schedules can be mapped out and used to forecast support quantities for the lifetime of the mine. Because the corrosion rates identified in Figures 2 and 3 are for bare steel, the support capacity loss estimates may need to be adjusted based on the types of support installed and the corrosion protection measures employed (discussed in Section 5). For example, for fully grouted rockbolts, the onset of support capacity loss can be modified based on the strain environment in addition to the corrosion environment, with high stress areas beginning to corrode much sooner than low stress areas due to the rock mass deformations damaging bolt encapsulation and enabling groundwater flow to the surface of the steel.

\subsection{Practical considerations}

This hazard mapping process should be refreshed through the lifetime of the mine as new areas are opened, new sampling data become available and observations of ground support performance become available for ground truthing the model. Additionally, sacrificial support (i.e. support elements which are non-critical for stability and safety) can be installed and retrieved via over coring to confirm estimates of corrosion rates. Similarly, corrosion tags can be used for atmospheric corrosion monitoring or can be placed within groundwater flows as an easy means of observing the effect of the local groundwater on carbon steel. 
If the support is expected to fail due to convergence or surpass its service life prior to corrosion induced failure, protective methods may not be necessary or less expensive means can be used. However, if corrosion is forecasted to be more aggressive than convergence, protective coatings or other treatments should be considered (discussed in the following section).

\section{Currently available protection measures}

Currently available corrosion protection methods were reviewed through correspondence with manufacturers, discussion with operating mines and review of white papers. Corrosion protection tends to fall into four broad categories: coatings, carbon steel alternatives, barrier protection and combinations. Coatings include epoxies, thermoplastics, zinc and/or aluminium galvanisation and bitumen or wax. Carbon steel alternatives include polymers (for mesh materials), fibreglass resin polymers and stainless steel. Barrier protection covers various cement and resin grouting regimes.

The key variables that should be reviewed when selecting protection means are the type of corrosion environment (i.e. acidic or saline) and the strain environment. Many coatings are capable of resisting corrosive environments but are brittle and will crack under strain, exposing unprotected steel and negating their effectiveness.

Stainless steel, depending on the grade, can be highly resistant to corrosion while maintaining elongation capacity. However, it tends to be very expensive and is not commonly applied in mining environments. Thermoplastic coatings are much more common in mining environments and provide a similar level of corrosion protection and elongation tolerance. Galvanisation is commonly applied to both bolts and mesh; however, it only offers corrosion resistance to saline groundwater and is generally brittle without significant tolerance for elongation.

Fully encapsulating support, either with cement or resin grout can provide acceptable corrosion protection with resins being more resistant to straining and cracking therefore providing better protection. Cement grout can provide excellent protection in low strain environments due to its chemical composition (Windsor 2004), but tends to crack and allow aggressive water through at relatively low strains (Bertuzzi 2004).

Coatings such as zinc galvanisation work in a similar way and can also be prone to damage and flaking during transport and installation depending on the coating type and grade (Evans 2013). The three main types of galvanisation in ascending order of resistance to corrosion and mechanical damage are: hot dip zinc, thermal diffusion zinc and zinc and aluminium galvanisation. Zinc galvanisation (hot dip and thermal diffusion) is commonly used in mining but these coatings do not protect from in acidic environments. Zinc and aluminium galvanisation is currently only applied to mesh elements but can resist acidic environments down to a pH of 2 .

Underground mines currently apply a combination of coatings (e.g. galvanisation or thermoplastics with full grouting to protect support elements). Underground mines with acidic groundwater commonly use thermoplastic coatings, encapsulation in grout or resin and larger diameter ground support. Figure 7 summarises the relative elongation capacity and corrosion resistance of various forms of protection and can assist with selecting appropriate corrosion protection means. Appendix Tables 1 to 3, provided at the end of this paper, summarise the reviewed protection methods in greater detail and provide relative characterisation of their resistance to corrosion, elongation capacity and durability (during handling and installation). 


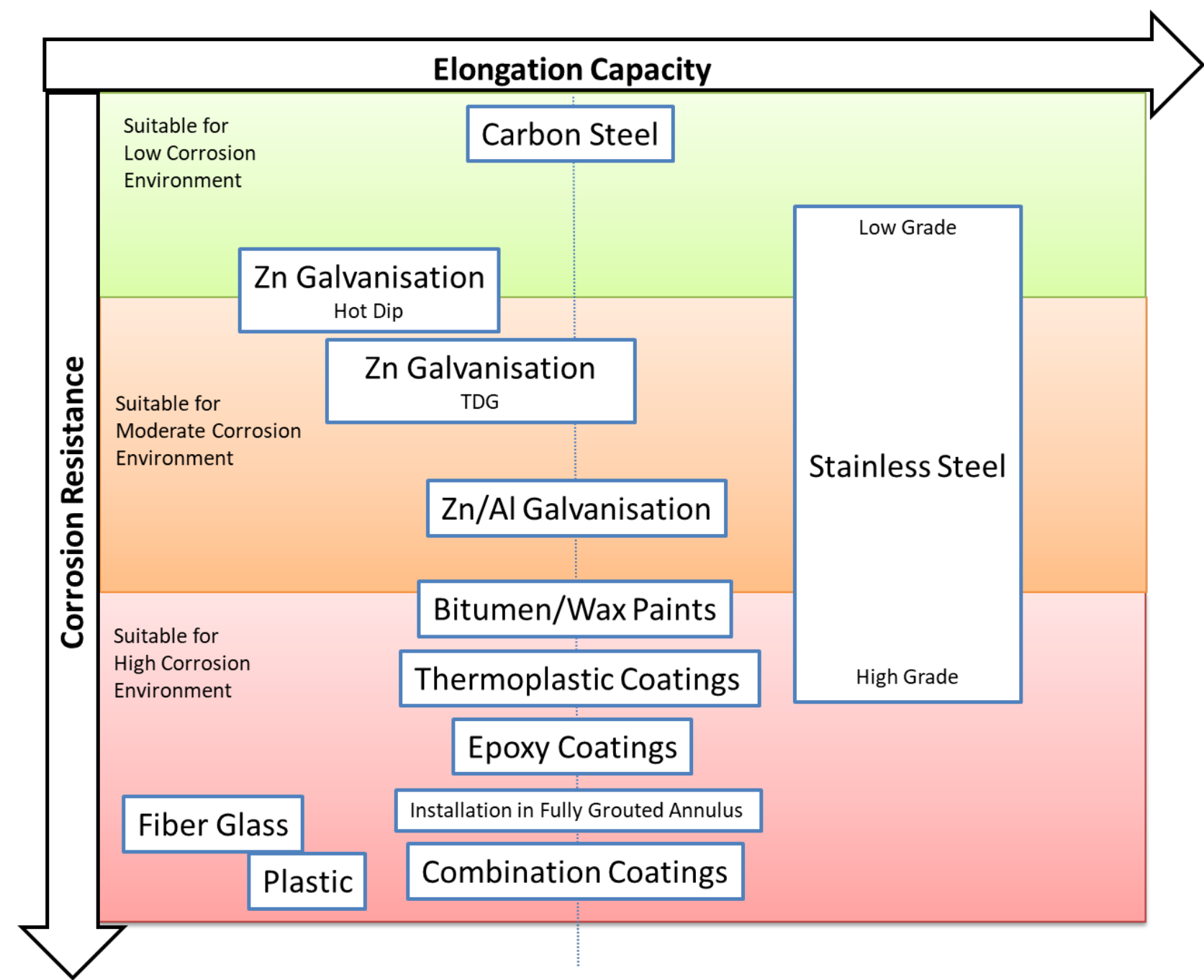

Notes: 1 - The corrosion resistance, elongation capacity and corrosion classification are relative scales. Considerations should be made for site specific requirements and corrosion conditions. 2 - In the case where corrosion protective coatings are applied, the elongation of the coating was considered over the underlying steel if the coating has lower elongation capacity than carbon steel. 3 -Zinc galvanisation is not recommended below a pH of 5.5 . 4 - The corrosion resistance and elongation properties of stainless steel are dependent on grade. TDG - Thermal diffusion galvanising.

Figure $7 \quad$ Relative corrosion resistance versus elongation capacity for different corrosion protection measures

\section{Conclusion}

Corrosive environments are common in mass mines which pose a potential risk to workers and production through the reduced lifespan of ground support elements. However, mechanisms driving corrosion rates are relatively well understood and the required data are commonly collected as parts of other common mine planning and operation tasks. Using the process presented here, estimated corrosion rates can be determined and overlain on mine plans to create corrosion hazard maps. The expected corrosion regime can then be compared to common means of ground support protection and used in conjunction with convergence calculations to develop a ground support replacement scheme that addresses both stress induced failure and corrosion induced failure before either cause ground instability.

\section{Acknowledgement}

The authors acknowledge Mackenzie Bromstad of Golder who shared her knowledge relating to geochemical assessments for mining projects. 


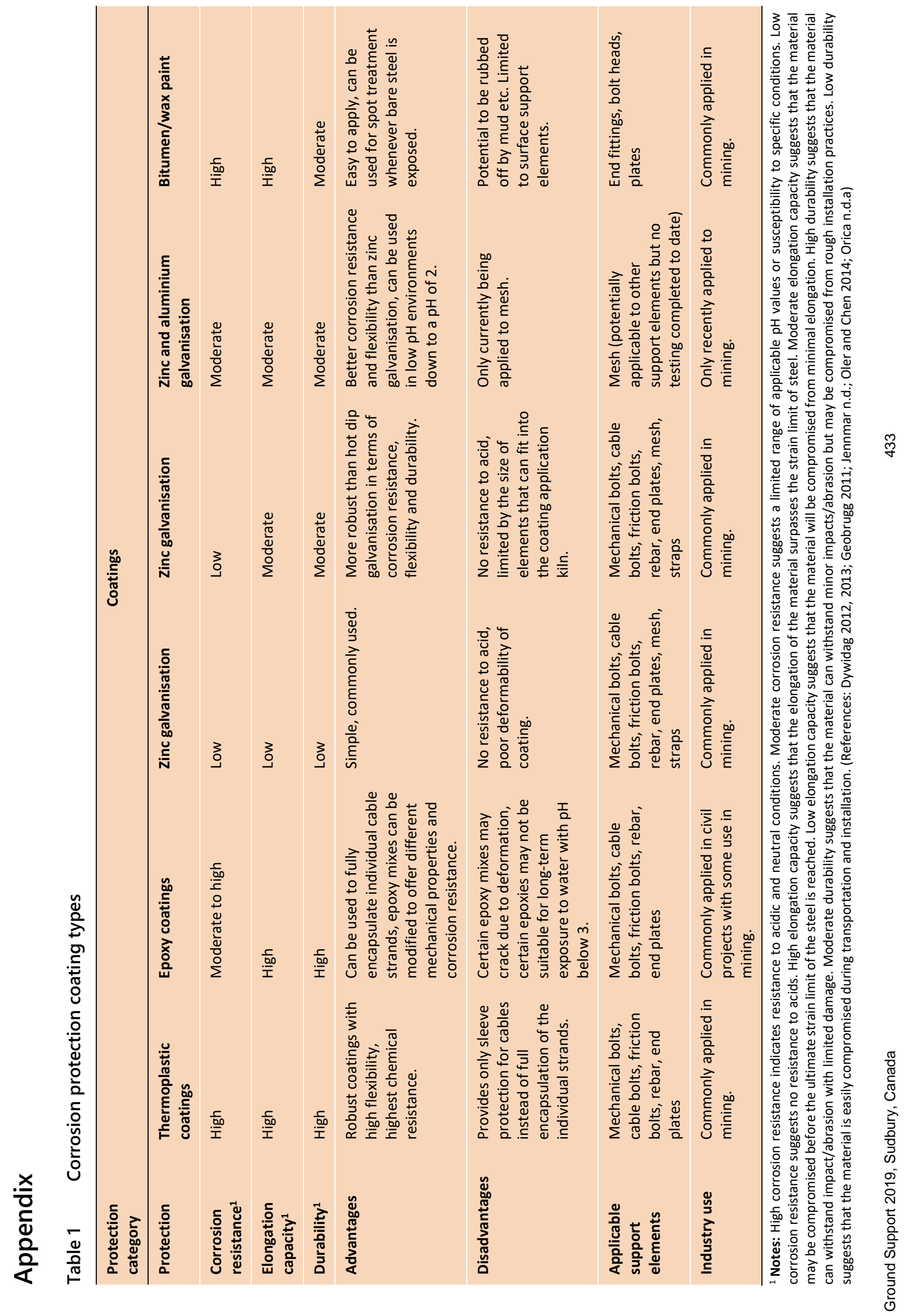




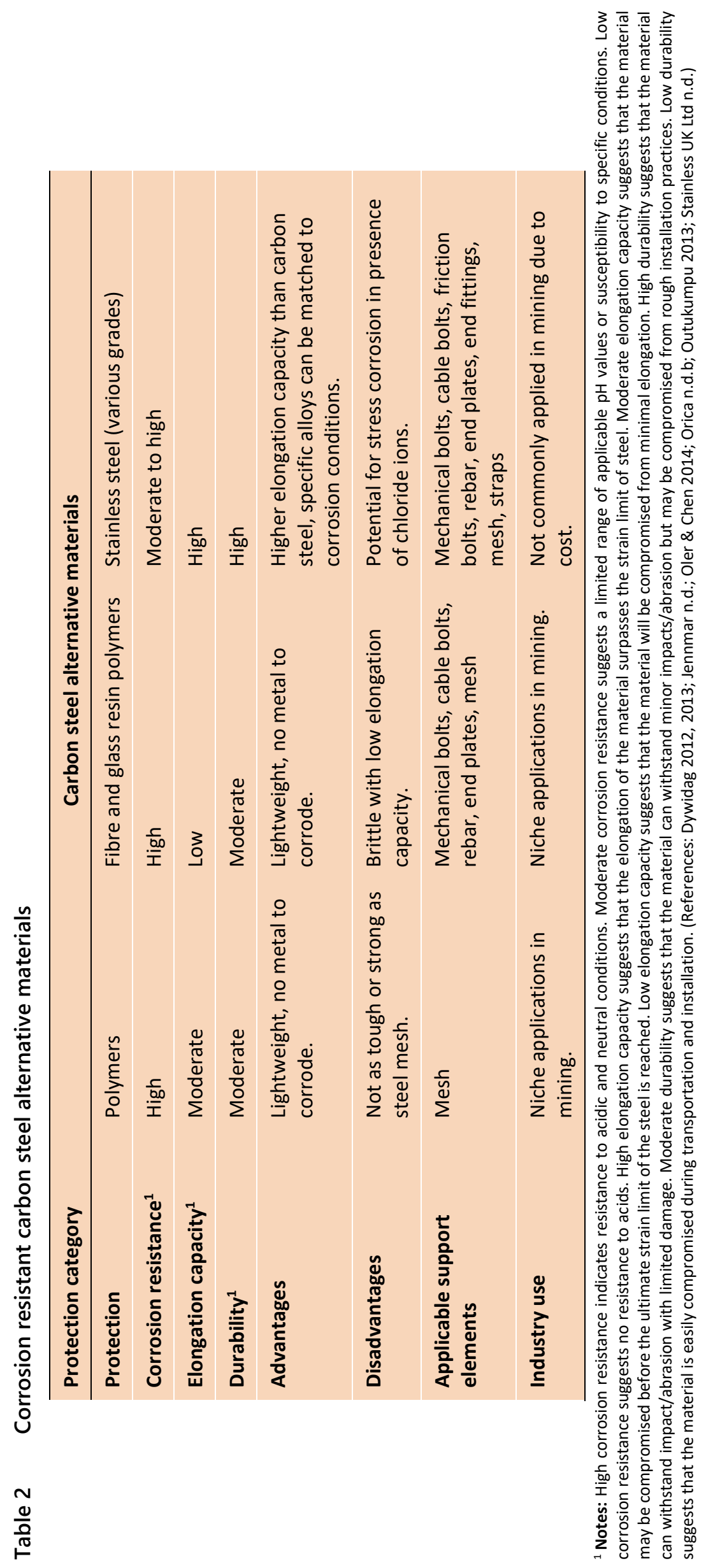




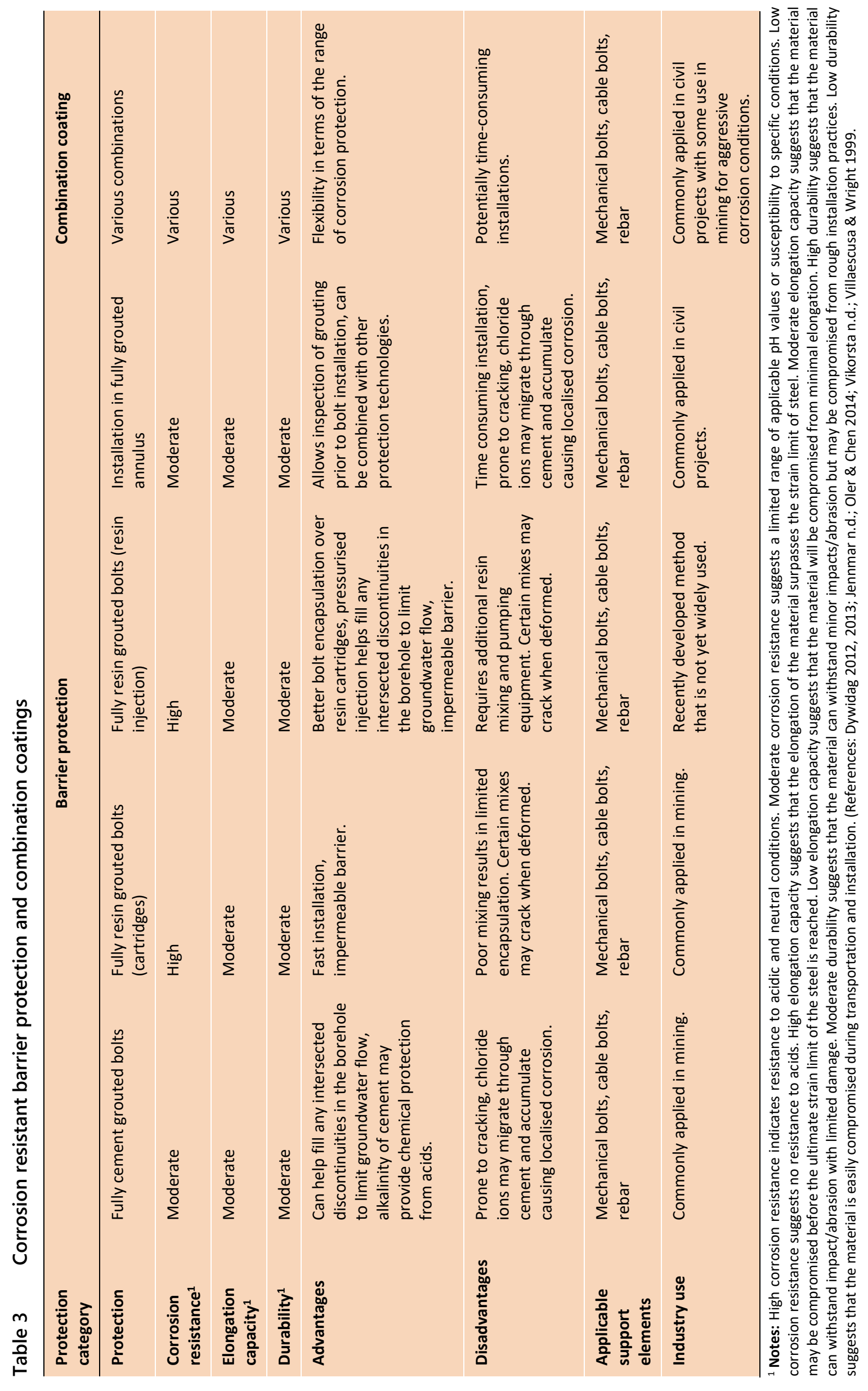




\section{References}

Bertuzzi, R 2004, '100-Year design life of rockbolts and shotcrete', in E Villaescusa \& Y Potvin (eds), Proceedings of the Fifth International Symposium on Ground Support: Ground Support in Mining and Underground Construction, A.A. Balkema, Rotterdam, pp. 425-430.

Bieniawski, ZT 1989, Engineering Rock Mass Classifications, Wiley, New York.

Charette, F 2003, 'Rockbolt corrosion in mining and tunneling', Atlas Copco, Talking Technically, pp. 26-28.

Charette, F, Germain, P \& Hadjigeorgiou, J 2004, 'Corrosion behaviour of Swellex bolts in underground mining environments', Canadian Institute of Mining, Annual General Meeting, Canadian Institute of Mining, Metallurgy and Petroleum, Montreal, $9 \mathrm{p}$.

Dorion, J 2013, La Corrosion du Soutenement Minier, PhD thesis, Laval University, Montreal.

Dorion, JF \& Hadjigeorgiou, J 2014, 'Corrosion considerations in design and operation of rock support systems', Mining Technology, vol. 123 , no. 2 , pp. 59-68.

Dorion, JF, Hadjigeorgiou, J \& Ghali, E 2009, 'Quantifying the rate of corrosion in selected underground mines', in M Diederichs \& G Grasselli (eds), ROCKENG09: Proceedings of the 3rd CANUS Rock Mechanics Symposium, paper 4031, $9 \mathrm{p}$.

Dorion, JF, Hadjigeorgiou, J \& Ghali, E 2015, 'Quantifying losses in support capacity due to corrosion', CIM Journal, vol. 6, no. 3, pp, 149-156.

Dywidag-Systems International 2012, Dywidag GRP Anchors and Bolts, brochure, Pasching.

Dywidag-Systems International 2013, Mining and Tunneling Products Catalogue, brochure, Pasching.

Evans, DW 2013, 'Emerging technologies in corrosion protection and acid resistance for ground support elements', in Y Potvin \& B Brady (eds), Proceedings of the Seventh International Symposium on Ground Support in Mining and Underground Construction, Australian Centre for Geomechanics, Perth, pp. 485-496.

Gamboa, E \& Atrens, A 2003, 'Environmental influence on the stress corrosion cracking of rock bolts', Engineering Failure Analysis, vol. 10, pp. 521-558.

Geobrugg 2011, Expected Lifetime Geobrugg Supercoating and Geobrugg Ultracoating, Los Algodones.

Hassell, R, Villaescusa, E \& Thompson, AG \& Kinsella, B 2004, 'Corrosion assessment of ground support systems', in E Villaescusa \& Y Potvin (eds), Proceedings of the Fifth International Symposium on Ground Support: Ground Support in Mining and Underground Construction, pp. 529-542.

Hassell, R, Villaescusa, E \& Thompson, A 2007, Corrosion of Rock Reinforcement in Underground Excavations, Volume 1, PhD thesis, Western Australian School of Mines, Perth.

Heidersbach, R 1990, Marine Corrosion, Metals Handbook Ninth Edition - Corrosion, vol. 13, pp. 893-926.

Hutchinson, DJ \& Diederichs, MS 1996, Cable Bolting in Underground Mines, BiTech Publishers Ltd., British Columbia.

Jennmar n.d., Selected Ground Control Products, brochure, Pittsburgh.

$\mathrm{Li}, \mathrm{C}$ \& Lindblad, K 1999, 'Corrosivity classification of the underground environment', in AG Thompson, E Villaescusa \& CR Windsor (eds), Rock Support and Reinforcement Practice in Mining: Proceedings of the International Symposium on Ground Support, A.A. Balkema, Rotterdam, pp. 69-75.

Oler, R \& Chen, J 2014, 'Introduction of a new superior coating on ground support products', Proceedings of the 33rd International Conference on Ground Control in Mining.

Orica n.d.a, Enduro Range, brochure, Victoria.

Orica n.d.b, Firep Bolts, brochure, Victoria.

Outokumpu 2013, Duplex Stainless Steel, brochure, Helsinki.

Roberge, PR 2000, Handbook of Corrosion Engineering, McGraw-Hill, New York.

Roberge, PR 2008, Corrosion Engineering Principles and Practice. McGraw-Hill, New York.

Roy, J, Preston, R \& Bewick, R 2016, 'Classification of aqueous corrosion in underground mines', Rock Mechanics and Rock Engineering, vol. 49, no. 8, doi:10.1007/s00603-016-0926-z

Schweitzer, PA 2007, Fundamentals of Metallic Corrosion: Atmospheric and Media Corrosion of Metals, CRC Press, Florida.

Stainless UK Ltd n.d., Products Brochure, brochure, Sheffield.

Vikorsta n.d., The Advantages of the CT-Bolt, Ørsta.

Villaescusa, E \& Wright, J 1999, 'Reinforcement of underground excavations using the CT bolt', in AG Thompson, E Villaescusa \& CR Windsor (eds), Rock Support and Reinforcement Practice in Mining: Proceedings of the International Symposium on Ground Support, A.A. Balkema, Rotterdam, 7 p.

Windsor, CR 2004, 'A review of long, high capacity reinforcing systems used in rock engineering', in E Villaescusa \& Y Potvin (eds), Proceedings of the Fifth International Symposium on Ground Support: Ground Support in Mining and Underground Construction, pp. 17-41. 